\title{
Effects of severely limited acquisition training and pretraining on the partial reinforcement effect ${ }^{\prime}$
}

\author{
E. J. CAPALDI AND ELIZABETH A. DEUTSCH \\ UNIVERSITY OF TEXAS
}

Following only five acquisition trials, partial reward produced greater resistance to extinction than consistent reward. This effect was obtained even when the animals were deprived of runway experience and goalbox feedings in pretraining.

In a systematic series of investigations, McCain (1966) reported a partial reinforcement extinction effect (PRE) following as few as 2-5 acquisition trials. McCain's findings are of considerable theoretical importance; they cast serious doubt on what is termed here the "threshold concept." According to the threshold notion, a critical number of either nonrewarded trials (e.g., Weinstock, 1954) or rewarded trials (e.g., Amsel, 1958; Lawrence \& Festinger, 1962) must be given in order to produce a PRE. Recently, Surridge, Rashotte, \& Amsel (1967) failed to obtain a PRE following four PR trials, either preceded by or not preceded by consistent reward. Accordingly, it was decided to determine if a PRE could be obtained following four PR trials preceded by a single rewarded trial. McCain's investigations employed considerable pretraining, alley exploration, etc. The Ss in this investigation either received or did not receive runway exploration and goalbox placements prior to running trials.

Method

The Ss were 24 Holtzman rats purchased in Madison, Wis. (14 female, 10 male) about 100 days old at the beginning of the experiment. The 10 males were originally assigned to another experiment and had received alley exploration and four .045-g 4-pellet placements in the goalbox, but not any other training. The females were given neither runway experience nor goalbox placements. The initial portion of the gray alley was an 8-in. floor treadle which, when depressed by the rat, whose front paws were always placed to its forward edge, started the first clock (.01 sec). Clock 1 was stopped (start time) and Clock 2 started when $S$ interrupted a photobeam 2 in. beyond the treadle. Clock 2 was stopped (run time) and Clock 3 started when $\mathrm{S}$ broke the second photobeam located 52 in. from the first. The last photobeam was 15-1/2 in. beyond the second photobeam (goal time) and 2-3/4 in. in front of a brass $2 \times 4 \times 1-1 / 2 \mathrm{in.} \mathrm{food} \mathrm{cup}$ covered by a sliding lid which opened automatically when the last photobeam was broken. There were two identical food cups, one for reinforced trials (wet mash) and one for nonreinforced trials. A manually- lowered guillotine door, 14 in. from the rear of the goal compartment, served to confine $S$ to the goal area.

Following 19 days of deprivation (12 g/day) Ss were handled on Days 20-28. Half the males and females were assigned to the partial group (P), the remaining half to the consistent group (C). On Day 29, the Ss were given a single rewarded acquisition trial $(2 \mathrm{~min}$ in goalbox). The Ss were run in the order CPPC, PCCP. On Day 30, Group $P$ received the schedule $N R, R, N R$, $R$, confinement on nonrewarded (NR) and rewarded (R) trials being $30 \mathrm{sec}$ with ITI being $30 \mathrm{sec}$. The PR sequence used here was the same as that which produced positive results in one of McCain's investigations and negative results in the investigation by Surridge et al. Group $C$ received four $R$ trials on Day 30. On Day 31, all Ss received 10 extinction trials, confinement duration and ITI remaining at $30 \mathrm{sec}$. An S was dropped from the experiment on Day 30 if any of the times on the four acquisition trials exceeded $50 \mathrm{sec}$. Two females were eliminated from Group $C$ and two from Group P, leaving these groups with five males (pretrained) and five females (nonpretrained) each.

Results

Group speeds (1/time) along the total length of the alley falled to differ significantly elther on the initial five trials of acquisition $(F=1.56)$ or on the initial extinction trial ( $F<1$ ). Figure 1 shows extinction speeds on the initial trial of extinction (A) and subsequently in blocks of three trials. An analysis over Trials 2-10 indicated that $R$ to $E$ was increased by partial reward $(F=9.28$, df $=1 / 16, p<.01)$, and by rewarded placements $(F=6.23, p<.05)$, but was unaffected by the interaction between reward schedule and placements (F<1). Mean speeds over Trials 2-10 were: partial placed, .93; partial nonplaced, .52; consistent placed, .45 ; and consistent nonplaced, .28.

Discussion

The threshold concept suggests that the animal's reaction to nonreward changes over trials (e.g., they eventually habituate to, or contrariwise, become frustrated by nonreward, etc.) and it is this change which is ultimately responsible for the PRE. Development of the processes responsible for the changed reaction, e.g., $\mathbf{r}_{\mathbf{g}}$, may occur elther in the training trials themselves or in pretraining. Thus the present results create serious difficulties for the threshold concept by showing that a PRE may be obtained following limited acquisition training even when runway experience 


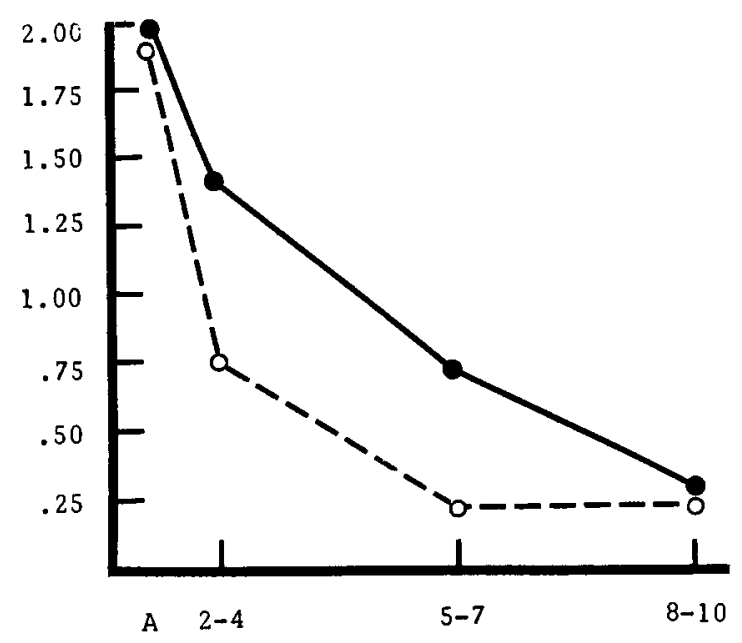

TRIAL BLOCKS

Fig. 1. Running speed in extinction on the initial nonrewarded trial of the day and subsequently in blocks of three trials.

and goalbox feedings are eliminated prior to the limited acquisition training. The results also suggest that the size of the small trial PRE, i.e., the difference between Groups $\mathbf{P}$ and $\mathbf{C}$, may be independent of prior runway experience and goalbox placements. However, caution is recommended here, since in this investigation sex and placements were confounded and several Ss were dropped from the nonpretrained groups. In any case it bears mentioning that threshold concepts of the frustration and dissonance variety seem to expect a reward schedule by goalbox placement interaction. It would seem, for example, that if $\mathbf{r}_{\mathrm{g}}$ is large prior to the running trials, the frustration hypothesis would predict that resistance to extinction should be decreased in the consistent condition and increased in the partial condition. A PRE has been obtained following 9 or 10 trials on several occasions (Bacon, 1962; Spence, Platt, \& Matsumoto, 1965; Spivey, in press) and even these results strain the threshold concept.

Surridge et al may have failed to obtain McCain's results because of an unorthodox experimental pro- cedure. While Ss were given a fixed amount of food in the goalbox, they were detained there for $90 \mathrm{sec}$ on all trials. Fehrer (1956), among others, has shown that detaining the animal in the goalbox after it has consumed the reward (postreinforcement delay) increases resistance to extinction. Thus Surridge et al may have inadvertently compared partial reward not with consistent reward but with postreinforcement delay, a procedure which increases resistance to extinction. Moreover, it is well known that extinction is faster the longer the nonrewarded confinement (e.g., Bacon, 1967; Capaldi, 1966). Another possibility is, then, that following limited training a 90 sec extinction confinement may have produced such rapid extinction in both the partial and "consistent" groups as to obscure differences between them.

\section{References}

AMSEL, A. The role of frustrative nonreward in non-continuous reward situations. Psychol Bull, 1958, 55, 102-119.

BACON, W. E. Partial reinforcement extinction effect following different amounts of training. J. comp. physiol. Psychol, 1962, 55, 9981003.

BACON, W. E. Resistance to extinction as a function of mode and time of removal from goalbox. Psychon. Sci, 1967, 3, 101-102.

CAPALDI, E. J. Stimulus specificity: nonreward. J. exp. Psychol., 1966, $72,410-414$.

FEHRER, E. Effects of amount of reinforcement and of pre- and postreinforcement delays on learning and extinction. J. exp. Psychol, $1956,52,167-175$.

LAWRENCE, D. H., \& FESTINGER, L. Deterrents and reinforcement. Stanford: Stanford University Press, 1962.

McCAIN, G. Partial reinforcement effects following a small number of acquisition trials. Psychon. Monogr. Suppl., 1966, 1, 12.

SPENCE, K. W., PLATT, J. R., \& MATSUMOTO, R. Intertrial reinforcement and the partial reinforcement effect as a function of number of training trials. Psychon. Sci, 1965, 3, 205-206.

SPIVEY, J. E. Resistance to extinction as a function of number of N-R transitions and percentage of reinforcement. $J$. exp. Psychol, in press.

SURRIDGE, C. T., RASHOTTE, M. E., \& AMSEL, A. Resistance to extinction of a running response after a small number of partially rewarded trials. Psychon. Sci., 1967, 7, 31-32.

WEINSTOCK, S. Acquisition and extinction of a partially reinforced running response at a 24 hour intertrial interval. J. exp. Psychol., $1958,56,151-158$.

Note

1. This research was supported in part by National Institute of Child and Health Development Research Grant HD 00949-04 to the first author. 